\title{
The effect of manganese supplementation on its concentrations in blood, hair, and organs of goat kids
}

\author{
Elizaveta Pitropovska ${ }^{1}$, Alena Pechová ${ }^{2}$, Kateřina Hauptmanová1 ${ }^{1}$ Tatána Husáková1, \\ Leoš Pavlata ${ }^{3}$
}

\begin{abstract}
${ }^{1}$ University of Veterinary and Pharmaceutical Sciences Brno, Faculty of Veterinary Medicine, Ruminant and Swine Clinic, ${ }^{2}$ Department of Biochemistry and Biophysics, Brno, Czech Republic

${ }^{3}$ Mendel University in Brno, Faculty of Agronomy, Department of Animal Nutrition and Forage Production, Brno, Czech Republic
\end{abstract}

Received February 12, 2014

Accepted May 28, 2014

\begin{abstract}
The aim of this study was to evaluate the effect of supplementation with an organic form of manganese on its concentration in blood, hair, and organs of goat kids. A total of 27 kids were divided into control and experimental groups on the day of their birth (Day 1). The kids were on mother's milk only diet until the day of weaning (Day 70). After weaning the kids received pellets at doses $0.3 \mathrm{~kg} / \mathrm{head} /$ day for next 70 days. The control group received pellets (manganese content $36.7 \mathrm{mg} / \mathrm{kg}$ ) and the experimental group received pellets with extra manganese addition in the form of manganese proteinate at the amount of $220 \mathrm{mg} / \mathrm{kg}$. Blood samples were taken on days 1, 70, 105, and 140; hair samples on days 1, 70, and 140. At the end of experiment, 7 kids from each group were slaughtered and samples of heart, liver, spleen, pancreas, kidney, muscle, and brain were taken. Manganese concentration was determined from fresh tissues after microwave digestion by electrothermal atomic absorption spectrophotometry. Kids of the experimental group had a significantly higher manganese concentration in the liver (4.90 vs. $3.06 \mathrm{mg} / \mathrm{kg}$ ), heart $(0.47$ vs $0.28 \mathrm{mg} / \mathrm{kg})$, kidney ( 1.29 vs. $0.87 \mathrm{mg} / \mathrm{kg})$, brain $(0.33$ vs $0.26 \mathrm{mg} / \mathrm{kg})$, and hair ( 4.25 vs. $3.14 \mathrm{mg} / \mathrm{kg}$ ) compared to the control group. The manganese concentration in blood was not affected by supplementation. Results of this study indicate that using the mentioned organs and hair for evaluation of the manganese status in an organism is more suitable than the determination of manganese concentration in blood.
\end{abstract}

Manganese proteinate, goat, tissue, liver, kidney

Manganese is an element essential to the metabolism and growth of organisms. Data about manganese metabolism in ruminants, and especially in goats are scarce. There is no available study describing in detail how to assess the concentration of manganese (Mn) supply in the animal body. In practice, the concentration of Mn supply in animals is estimated by determining the Mn concentration in serum or in whole blood. The advantage of estimating the Mn concentration in whole blood is a lower risk of measurement error, as the sample haemolysis can significantly distort the concentration of $\mathrm{Mn}$ in blood plasma or serum (Herdt and Hoff 2011). There are only few data on Mn concentration in serum of goats and to the authors' knowledge, there is no work describing Mn concentration in the whole blood of goats. Therefore, more research is necessary in this field.

Likewise, there are very few studies on the determination of $\mathrm{Mn}$ concentration in organs and in hair. The study by Haenlein and Anke (2011) reported that Mn-deficient nutrition has no impact on the Mn concentration in blood serum of goats but it reduces the Mn content in organs (liver, kidney, heart, muscle) and hair. Skibniewski et al. (2010) reported that hair is a very good indicator of the degree of manganese supply in animals. Hair acts as a recording filament because elements are deposited in the hair matrix within a short time and are removed from active metabolism as the hair shaft grows from the follicle (Combs et al. 1982). 
Manganese is one of the trace elements, which is regularly supplemented even if deficiency is only suspected but not confirmed. Trace elements are supplemented by inorganic and in latest years also organic forms. Some studies mentioned a great potential for manganese sources of enhanced nutritive value, protected by complexation with peptides (the so-called 'chelates' and 'proteinates') (Underwood and Suttle 1999). Henry et al. (1992) compared three forms of manganese in lambs. Based on the Mn concentration in the liver, kidneys, and bones, they established the highest bioavailability for Mn-methionine, lower availability for $\mathrm{MnSO}_{4}$, and the lowest for the $\mathrm{MnO}$ form. For the above reasons we chose the organic form of $\mathrm{Mn}$ supplementation in our study. The aim of our study was to evaluate the Mn content in whole blood, hair and organs of kids, and also to assess how supplementation of organic manganese influences the manganese distribution in the organism of kids and their body growth.

\section{Materials and Methods}

Animals and the experimental design

The experiment was performed at the Ruminant and Swine Clinic of the University of Veterinary and Pharmaceutical Sciences Brno after the approval of the Ethics Committee (No. 33/2012). Manganese supplementation of the mother goats started 2 months before the expected date of delivery, and continued after the delivery until weaning. The control group of mother goats $(n=6)$ received a feed mixture without Mn supplementation (natural Mn content: $21.5 \mathrm{mg} / \mathrm{kg}$ ). Mothers goats of the experimental group $(\mathrm{n}=7)$ received a feed mixture enriched with Mn proteinate (Bioplex Mn, Alltech, USA) at the amount of $220 \mathrm{mg} / \mathrm{kg}$.

Our experiment with goat kids started on the day of their birth (Day 1). A total of 13 kids were born in the control group, and 14 were born in the experimental group; the distribution of kids was based on their mothers' nutrition. All kids were on a mother's milk diet until the day of weaning. The kids were weaned at the age of $70 \pm 5$ days.

After weaning, all kids were fed an identical diet which differed only in the content of manganese in the feed mixture. The composition of feed mixture is shown in Table 1. The kids had access to hay, water and salt lick ad libitum. The mean concentration of $\mathrm{Mn}$ in meadow hay was $88.28 \pm 8.88 \mathrm{mg} / \mathrm{kg}$. The feed mixture was administered in pellets form at a dose of $300 \mathrm{~g}$ per head per day. The appropriate amount of supplementary diet ( $150 \mathrm{~g}$ per one feeding two times for day) was added in the individual groups into the common feeders that were of a size that enabled all animals to eat at the same time. The control group $(n=13)$ received feed mixture without Mn supplementation (natural Mn content: $36.7 \mathrm{mg} / \mathrm{kg}$ ). Kids in the experimental group $(\mathrm{n}=14)$ received a feed mixture enriched with $\mathrm{Mn}$ in the form of Mn proteinate (Bioplex Mn, Alltech, USA) at the amount of $220 \mathrm{mg} / \mathrm{kg}$. The supplementation continued for 70 days after the weaning (from day 70 to day 140).

Table 1. Nutrient content in the feed mixture.

\begin{tabular}{lrlr}
\hline Dry matter $(\mathrm{g})$ & 886.00 & Sodium $(\mathrm{g})$ & 2.96 \\
Net energy of lactation (MJ) & 6.31 & Potassium $(\mathrm{g})$ & 9.17 \\
Crude protein $(\mathrm{g})$ & 171.81 & Iodine $(\mathrm{mg})$ & 1.51 \\
Metabolizable energy (MJ) & 10.44 & Manganese (mg) control group & 36.70 \\
Fibre $(\mathrm{g})$ & 78.24 & Manganese (mg) experimental group & 256.70 \\
Fat $(\mathrm{g})$ & 29.06 & Iron (mg) & 79.33 \\
Calcium (g) & 7.90 & Copper (mg) & 29.42 \\
Phosphorus $(\mathrm{g})$ & 7.96 & Zinc (mg) & 114.62 \\
Magnesium $(\mathrm{g})$ & 2.19 & & \\
\hline
\end{tabular}

\footnotetext{
Analytical procedures

Blood sampling and weighing of kids were performed on days 1, 70, 105, and 140 of the experiment. Blood was taken from v. jugularis into heparinised tubes to determine the concentration of Mn. The kids' hair was sampled to determine the concentration of Mn. Hair samples were collected on the day of birth (Day 1), on the day of weaning (Day 70) and at the end of the experiment (Day 140) from the same area after it was cleaned with a brush. At the end of the experiment, 7 kids from each group were slaughtered for Mn distribution to be evaluated in organs and tissues. After the slaughter, samples were collected from the thigh muscle (m. semitendinosus), myocardium, liver, pancreas, spleen, kidneys, and brain. Collected samples were deep-frozen at $-18{ }^{\circ} \mathrm{C}$ until the time of processing in the laboratory.
} 
Samples were analysed in the clinical laboratory for large animals at the Faculty of Veterinary Medicine, University of Veterinary and Pharmaceutical Sciences Brno. Samples of hair were subsequently processed in the laboratory using the modified method of Pavlata et al. (2011). Before determining the concentrations of manganese, samples of whole blood, various tissues, and hair were digested in a closed system with the addition of hydrogen peroxide and nitric acid in the MLS - 1200 digestion unit (Milestone, Italy). From the digested product we determined the concentration of Mn applying electrothermal atomic absorption spectrophotometry using the ZEEnit 700P spectrometer (Unicam, Great Britain).

\section{Statistical analysis}

The Mn concentrations in blood and hair were evaluated with the ANOVA (two-factor test with replication). Significant differences were further analyzed with HSD-Tukey's test. Mn concentration in organs were statistically evaluated with F-test to determine the variability of individual files, and based on its outcome we applied Student's $t$-test for files with identical/different variances. Results are presented as mean values with standard error of the mean (SEM). The statistical analysis was performed in Excel (Microsoft Windows XP) and in software Statistica 8.0 (StatSoft CR s.r.o.).

\section{Results}

The concentration of $\mathrm{Mn}$ in whole blood of kids ranged from 5.24 to $10.07 \mu \mathrm{g} / \mathrm{l}$ during the entire experiment. The results of ANOVA showed that the concentration of manganese in whole blood of kids was significantly influenced by the time of sampling $(P \leq 0.001)$ but not by manganese supplementation to the diet. The results are shown in Table 2 .

Table 2. Mean manganese concentration $(\mu \mathrm{g} / \mathrm{l})$ in whole blood of goat kids (means \pm SEMs) at the day of birth (1), the day of weaning (70), day 35 of supplementation (105), and at the end of the experiment (140).

\begin{tabular}{cccc}
\hline Day of experiment & Control group $(\mathrm{n}=13)$ & Experimental group $(\mathrm{n}=14)$ & $P$ value \\
\hline 1 & $5.24 \pm 0.32$ & $7.10 \pm 0.73$ & $\mathrm{~ns}$ \\
70 & $7.51 \pm 0.44$ & $7.49 \pm 0.59$ & $\mathrm{~ns}$ \\
105 & $10.07 \pm 0.99^{\mathrm{A}}$ & $9.17 \pm 0.78$ & $\mathrm{~ns}$ \\
140 & $8.79 \pm 0.82^{\mathrm{A}}$ & $8.43 \pm 0.66$ & $\mathrm{~ns}$ \\
\hline
\end{tabular}

ns - non-significant differences between groups $(P>0.05)$

${ }^{\mathrm{A}} P \leq 0.001$ - significant differences compared with Day 1

Table 3. Mean manganese concentration $(\mathrm{mg} / \mathrm{kg})$ in hair of goat kids (means \pm SEMs) at the day of birth (1), the day of weaning (70) and at the end of the experiment (140).

\begin{tabular}{cccc}
\hline Day of experiment & Control group $(\mathrm{n}=13)$ & Experimental group $(\mathrm{n}=14)$ & $P$ value \\
\hline 1 & $1.73 \pm 0.08$ & $2.10 \pm 0.23$ & $\mathrm{~ns}$ \\
70 & $3.89 \pm 0.16^{\mathrm{A}}$ & $5.45 \pm 0.33^{\mathrm{A}}$ & $* * *$ \\
140 & $3.14 \pm 0.19^{\mathrm{A}}$ & $4.25 \pm 0.36^{\mathrm{A}}$ & $*$ \\
\hline
\end{tabular}

$* * P \leq 0.05, * * * P \leq 0.001$ significant differences between group, ns - non-significant

${ }^{\mathrm{A}} P \leq 0.001$ - significant differences compared with Day 1

The Mn concentration in the kids' hair showed high variability. The results of ANOVA showed that the $\mathrm{Mn}$ concentration in hair was significantly affected by manganese supplementation to the diet $(P \leq 0.001)$ and by the time of sampling $(P \leq 0.001)$. Tukey post-hoc test showed significantly higher values in the experimental group on the day of weaning $(P \leq 0.001)$ and at the end of the experiment $(P \leq 0.05)$. The results are shown in Table 3.

The mean concentrations of $\mathrm{Mn}$ in individual organs are shown in Table 4. The highest concentrations of Mn were detected in the liver, followed by pancreas and kidneys. In all 
Table 4. Mean manganese concentration ( $\mathrm{mg} / \mathrm{kg}$ wet tissue) in kid's organs (means $\pm \mathrm{SEMs)} \mathrm{of} \mathrm{the} \mathrm{control}$ group and the group supplemented with manganese proteinate.

\begin{tabular}{lccc}
\hline Organs & Control group $(\mathrm{n}=7)$ & Experimental group $(\mathrm{n}=7)$ & $P$ value \\
\hline Liver & $3.06 \pm 0.29$ & $4.90 \pm 0.37$ & $* *$ \\
Kidney & $0.87 \pm 0.04$ & $1.29 \pm 0.10$ & $* * *$ \\
Heart & $0.28 \pm 0.03$ & $0.47 \pm 0.03$ & $\mathrm{~ns}$ \\
Muscle & $0.08 \pm 0.003$ & $0.09 \pm 0.009$ & $\mathrm{~ns}$ \\
Spleen & $0.19 \pm 0.02$ & $0.16 \pm 0.02$ & $\mathrm{~ns}$ \\
Pancreas & $1.73 \pm 0.11$ & $1.44 \pm 0.12$ & $*$ \\
Brain & $0.26 \pm 0.03$ & $0.33 \pm 0.02$ & \\
\hline
\end{tabular}

** $P \leq 0.05 ; * * P \leq 0.01 ; * * * P \leq 0.001$ significant differences between groups

ns - non-significant

organs of kids in the experimental group (except spleen and pancreas) higher concentrations of Mn were found compared to the control group. Significant differences between groups were found in the liver, kidneys $(P \leq 0.01)$, heart $(P \leq 0.001)$, and brain $(P \leq 0.05)$.

There were no significant differences in the weight of kids in the control and experimental groups throughout the experiment. The mean weight in control vs. experimental group was as follows: on the day of birth $3.25 \pm 0.09$ vs. $3.29 \pm 0.22$; on the day of weaning $18.21 \pm$ 0.60 vs. $19.03 \pm 0.98 \mathrm{~kg}$; Day 105 of experiment $22.38 \pm 0.93$ vs. $23.21 \pm 1.32 \mathrm{~kg}$; Day 140 of experiment $26.97 \pm 1.01$ vs. $26.43 \pm 1.49 \mathrm{~kg}$.

\section{Discussion}

Comparison of our results with literature is difficult because to our knowledge there are no studies monitoring the concentration of manganese in whole blood of goats. Our findings concerning Mn concentration in whole blood are similar to those published for dairy cows $14.0 \pm 3.2 \mu \mathrm{g} / \mathrm{l}$ (Pechova et al. 2008) and 5.10-12.35 $\mu \mathrm{g} / \mathrm{l}$ (Gehrke and Lachowski 1997). However, our results were lower than $20 \mu \mathrm{g} / 1$, which is recommended for diagnostic of manganese deficiency in ruminants (Hidiroglou et al. 1978; Underwood and Suttle 1999) even though we used high doses of supplemented manganese $(220 \mathrm{mg} / \mathrm{kg}$ feed mixture). We chose this dose based on our experience that supplementation of granulated feed mixture with Mn lower than $140 \mathrm{mg} / \mathrm{kg}$ did not influence the concentration of $\mathrm{Mn}$ in blood of goats, and the values were still under limits recommended for the diagnosis of manganese deficiency.

We can conclude that for goats the marginal band of $20 \mu \mathrm{g} / \mathrm{l}$ of $\mathrm{Mn}$ in whole blood is too high.

In our study we did not find higher concentrations of $\mathrm{Mn}$ in the blood of the experimental group of kids, which did not correspond with our expectations as blood is recommended for the evaluation of manganese supply. Some studies report good correlation between the manganese intake and its concentration in blood; e.g., Rojas et al. (1965) established the concentration in blood of cows to be $18.1 \mu \mathrm{g} / \mathrm{l}$ of Mn with the Mn concentration in diet at $15.8 \mathrm{mg} / \mathrm{kg}$, and $27.8 \mu \mathrm{g} / \mathrm{l}$ of $\mathrm{Mn}$ with the diet concentration of $25.1 \mathrm{mg} / \mathrm{kg}$. Similarly, Hidiroglou et al. (1978) described an increase of Mn concentration in blood of sheep with the increase of dietary $\mathrm{Mn}$ from 5 to $60 \mathrm{mg} / \mathrm{kg}$. Nevertheless, other works describe opposite results. Legleiter et al. (2005) found no effect of manganese supplementation on its concentration in blood plasma of steers. In their study the control group had minimal dietary Mn content of $8.1 \mathrm{mg} / \mathrm{kg}$ of dry matter (DM). On the basis of our study manganese concentration in whole blood is not good indicator for assessment of manganese status 
of goat kids. It is necessary to conduct more experiments for more precise evaluation of factors that influence Mn concentration in blood.

Our results show that the Mn concentration in hair reflects better the dietary intake of $\mathrm{Mn}$. Higher concentration of $\mathrm{Mn}$ in the hair of kids from the experimental group at the time of weaning is a result of their mothers' supplementation. The Mn concentration in the hair which we established is higher than the values published in hair of goats $(2.1 \pm$ $1.1 \mathrm{mg} / \mathrm{kg}$ of DM) with the Mn content in the diet $60 \mathrm{mg} / \mathrm{kg}$ of DM (Haenlein and Anke 2011). The effect of maternal supplementation on the concentration of $\mathrm{Mn}$ in the hair of newborn calves was observed in the earlier study by Howes and Dyer (1971). These authors found an average concentration of Mn between 4.27 and $5.59 \mathrm{mg} / \mathrm{kg}$ of DM, while the higher supplementation was reflected only by marginal increase in the concentration of $\mathrm{Mn}$ in the hair of calves. However, the Mn concentrations in the $\operatorname{diet}(21,13,14 \mathrm{mg} / \mathrm{kg})$ were much lower compared to our experiment. The relationship between Mn supplementation and its concentrations in the hair of lambs was confirmed by Lassiter and Morton (1968) who found the Mn concentration in the hair of lambs $6.1 \mathrm{mg} / \mathrm{kg}$ with $0.8 \mathrm{mg} / \mathrm{kg} \mathrm{Mn}$ in the diet and $18.7 \mathrm{mg} / \mathrm{kg}$ with $29.9 \mathrm{mg} / \mathrm{kg} \mathrm{Mn}$ in the diet. These values are substantially higher than those demonstrated in our experiment. The reason for this difference can probably be explained by differences in species, age and nutrition of the observed animals.

The concentration of manganese in the body organs of kids also reflects manganese supplementation of the diet. The highest concentrations of manganese were found in the liver and kidneys. The concentrations of manganese which we detected were higher than those stated by Frank et al. (2000) in male goats; they found $2.19 \pm 0.68 \mathrm{mg} /$ $\mathrm{kg}$ in liver and $0.55 \pm 0.12 \mathrm{mg} / \mathrm{kg}$ in kidneys. Graham et al. (1994) detected a higher variability in dairy cows, showing Mn concentration in liver between 1.43 and $5.60 \mathrm{mg} /$ $\mathrm{kg}$. Similar Mn concentrations were reported by Falandysz (1993) in dairy cows where the $\mathrm{Mn}$ concentration in liver ranged from 0.64 to $4.0 \mathrm{mg} / \mathrm{kg}$, in kidneys from 0.42 to $3.1 \mathrm{mg} / \mathrm{kg}$ and in muscles from 0.01 to $0.85 \mathrm{mg} / \mathrm{kg}$. Other studies monitoring the concentration of manganese in the goat organs state values for dry matter and therefore it is difficult to compare with our values detected in fresh tissue. Lengarite et al. (2012) found the $\mathrm{Mn}$ concentration in goat liver between 6.85 and $13.65 \mathrm{mg} / \mathrm{kg} \mathrm{DM}$. Haenlein and Anke (2011) reported Mn concentration of $4.1 \pm 2.1 \mathrm{mg} / \mathrm{kg} \mathrm{DM}$ in the liver of goats with Mn deficiency and $10.1 \pm 3.3 \mathrm{mg} / \mathrm{kg} \mathrm{DM}$ with $60 \mathrm{ppm} \mathrm{Mn}$ in the diet. Underwood and Suttle (1999) recommended 3.0-6.0 mg/kg DM in goat liver as marginal values for the diagnosis of manganese deficiency. Since the average dry matter content in the liver varies between 20 and 36\% (Rosendo and McDowell 2003), we can say that the kids from both groups in our experiment were sufficiently supplied with manganese.

The positive effect of supplementation on the concentration of manganese in the body organs was already confirmed in earlier studies (Rojas et al. 1965; Lassiter and Morton 1968). Similarly, Legleiter et al. (2005) and Hansen et al. (2006) found a positive effect of $\mathrm{MnSO}_{4}$ supplementation on the Mn concentration in the liver of cattle.

The supplementation with organic manganese in the diet of goat kids had no significant influence on the Mn concentration in whole blood. The manganese supplementation significantly increased the concentration of manganese in the hair and in some organs and tissues. Higher values were detected in the liver, kidneys, heart, and brain in the experimental group of kids. Results of this study indicate that the use of these organs and hair for evaluation of Mn status in organism is better than determination of Mn concentration in blood.

\section{Acknowledgement}

This research was supported by grants 121683/FVL of IGA of VFU and by Visegrad Fund (project 51100926). We would like to thank the members of Laboratory for Large Animals and technical personnel of the Ruminant Clinic. 


\section{References}

Combs DK, Goodrich RD, Meiske JC 1982: Mineral concentrations in hair as indicators of mineral status: a review. J Anim Sci 54: 391-398

Falandysz J 1993: Some toxic and essential trace metals in cattle from the northern part of Poland. Sci Total Environ 136: 177-191

Frank A, Danielsson R, Jones B 2000: Experimental copper and chromium deficiency and additional molybdenum supplementation in goats II. Concentrations of trace and minor elements in liver, kidneys and ribs: haematology and clinical chemistry. Sci Total Environ 249: 143-170

Gehrke M, Lachowski A 1997: Determination of manganese in cow blood using the flameless atomic absorption spectrophotometry II. Population investigations into the variability of manganese concentrations in the serum and blood of cows in varios production stage. Bull Vet Inst Pulawy 41: 115-119

Graham TW, Thurmond MC, Mohr FC, Holmberg CA, Anderson ML, Keen CL 1994: Relationships between maternal and fetal liver copper, iron, manganese, and zinc concentrations and fetal development in California Holstein dairy cows. J Vet Diagn Invest 6: 77-87

Haenlein GFW, Anke M 2011: Mineral and trace element research in goats: A review. Small Rumin Res 95: 2-19

Hansen SL, Spears JW, Lloyd KE, Whisnant CS 2006: Growth, reproductive performance, and manganese status of heifers fed varying concentrations of manganese. J Anim Sci 84: 3375-3380

Henry PR, Ammerman CB, Littell RC 1992: Relative bioavailability of manganese from a manganese-methionine complex and inorganic sources for ruminants. J Dairy Sci 75: 3473-3478

Herdt TH, Hoff B 2011: The use of blood analysis to evaluate trace mineral status in ruminant livestock. Vet Clin Food Anim 27: 255-283

Hidiroglou M, Ho SK, Ivan M, Shearer DA 1978: Manganese status of pasturing ewes, of pregnant ewes and doe rabbits on low manganese diets and of dairy cows with cystic ovaries. Can J Comp Med 42: 100-107

Howes AD, Dyer IA 1971: Diet and supplemental mineral effects on manganese metabolism in newborn calves. J Anim Sci 32: 141-145

Lassiter JW, Morton JD 1968: Effects of a low manganese diet on certain ovine characteristics. J Anim Sci 27: 776-779

Legleiter LR, Spears JW, Lloyd KE 2005: Influence of dietary manganese on performance, lipid metabolism, and carcass composition of growing and finishing steers. J Anim Sci 83: 2434-2439

Lengarite MI, Mbugua PN, Gachuiri CK, Kabuage LW 2012: Mineral status of sheep and goats grazing in the Arid Rangelands of Northern Kenya. Pak J Nutr 11: 383-390

Pavlata L, Chomat M, Pechova A, Misurova L, Dvorak L 2011: Impact of long-term supplementation of zinc and selenium on their content in blood and hair in goats. Vet Med 56: 63-74

Pechova A, Pavlata L, Dvorak R, Lokajova E 2008: Contents of $\mathrm{Zn}, \mathrm{Cu}, \mathrm{Mn}$ and Se in milk in relation to their concentrations in blood, milk yield and stage of lactation in dairy cattle. Acta Vet Brno 77: 523-531

Rojas MA, Dyer IA, Cassatt WA 1965: Manganese deficiency in the bovine. J Anim Sci 24: 664-667

Rosendo O, McDowell LR 2003: Liver dry matter and liver lipids in periparturient dairy cows. Acta Vet Brno 72: $541-546$

Skibniewski M, Kosla T, Skibniewska EM 2010: Manganese status in free ranging european bisons from Bialowieza Primeval Forest. Bull Vet Inst Pulawy 54: 429-432

Underwood EJ, Suttle NF 1999: Manganese. In: Underwood EJ, Suttle NF (Eds): The Mineral Nutrition of Livestock, $3^{\text {rd }}$ Edition, CABI Publishing, Wallingford, pp. 397-414 